\title{
Hydraulic jumps: turbulence and air bubble entrainment
}

\author{
Hubert CHANSON
}

\author{
The University of Queensland \\ School of Civil Engineering, Brisbane QLD 4072, Australia \\ h.chanson@uq.edu.au
}

\begin{abstract}
A free-surface flow can change from a supercritical to subcritical flow with a strong dissipative phenomenon called a hydraulic jump. Herein the progress and development in turbulent hydraulic jumps are reviewed with a focus on hydraulic jumps operating at large Reynolds numbers typically encountered in natural streams and hydraulic structures. The key features of the turbulent hydraulic jumps are the highly turbulent flow motion associated with some intense air bubble entrainment at the jump toe. The state-of-the-art on the topic is discussed based upon recent theoretical analyses and physical data.
\end{abstract}

Key words : Hydraulic jumps, Turbulence, Air bubble entrainment, Theory, Dynamic similarity, Physical modelling, Numerical modelling.

\section{Le ressaut hydraulique: turbulence et entraînement d'air}

\begin{abstract}
RÉSUMÉ. - La transition d'un écoulement à surface libre torrentiel en un écoulement fluvial s'effectue avec un processus dissipatif, appelé un ressaut hydraulique. Dans cette synthèse, on décrit les développements récents des connaissances sur les ressauts hydrauliques turbulents, avec grands nombres de Reynolds, qui sont typiques des écoulements dans les rivières et dans les ouvrages hydrauliques. Les caractéristiques principales de ces ressauts sont le caractère extrêmement turbulent de l'écoulement, couplé à un entrainement important d'air dans le rouleau de déferlement. On discute les derniers développements en se basant sur les équations théoriques et des résultats physiques.
\end{abstract}

Mots clefs : ressaut hydraulique, turbulence, entraînement d'air, modèle physique, modèle numérique, similarité dynamique

\section{INTRODUCTION}

A free-surface flow can change from subcritical to supercritical in a relatively smooth manner at a weir crest. The flow regime evolves with the occurrence of critical flow conditions associated with relatively small energy loss [20]. On the other hand, the transition from supercritical to subcritical flow is characterised by a strong dissipative mechanism, called a hydraulic jump (Fig. 1 to 3). A hydraulic jump is an extremely turbulent flow associated with the development of large-scale turbulence, surface waves and spray, energy dissipation and air entrainment. Figure 1 shows a hydraulic jump stilling basin downstream of a spillway during a major flood. Figure 2 shows a small hydraulic jump in an irrigation channel, and Figure 3 presents a hydraulic jump in the Todd River (Australia). The dark colour of the waters highlights the strong sediment load in the natural system (Fig. 3). The flow within a hydraulic jump is extremely complicated [19], and it remains a challenge to scientists and researchers [7], [34].

The key features of hydraulic jumps in natural systems and hydraulic structures are the turbulent nature of the flow and the air entrapment at the jump toe associated with intense air-water mixing in the hydraulic jump roller, for example seen in Figures 1 to 3 . The turbulence measurements in hydraulic jumps are limited, but for the pioneering study of Rouse et al. [19] and the hot-film data of Resch and

1. Corresponding author
Leutheusser [46]. The first two-phase flow measurements in hydraulic jumps were performed in India by Rajaratnam [41] and Thandaveswara [50]. An important study was the work of Resch and Leutheusser [47] highlighting the effects of the inflow conditions on the air entrainment and momentum transfer processes. In the last fifteen years, some significant advances included Chanson [4], [6], [10], Mossa and Tolve [32], Chanson and Brattberg [11], Murzyn et al. [37], [38] and Rodriguez-Rodriguez et al. [48].

This paper reviews the progress and development in the understanding of turbulence and air-water flow properties of hydraulic jumps. The focus is on the turbulent hydraulic jump with a marked roller operating with high-Reynolds numbers; such flow conditions are typical of natural rivers and hydraulic structures. These hydraulic jumps are characterised by some complicated turbulent air-water flow features.

\section{THEORETICAL APPROACH}

\section{II.1. Momentum considerations}

In a hydraulic jump, the transition from supercritical to subcritical flows is associated with a sudden rise in the freesurface elevation and a discontinuity of the pressure and velocity fields. The integral form of the equations of conservation of mass and momentum gives a series of relationships 


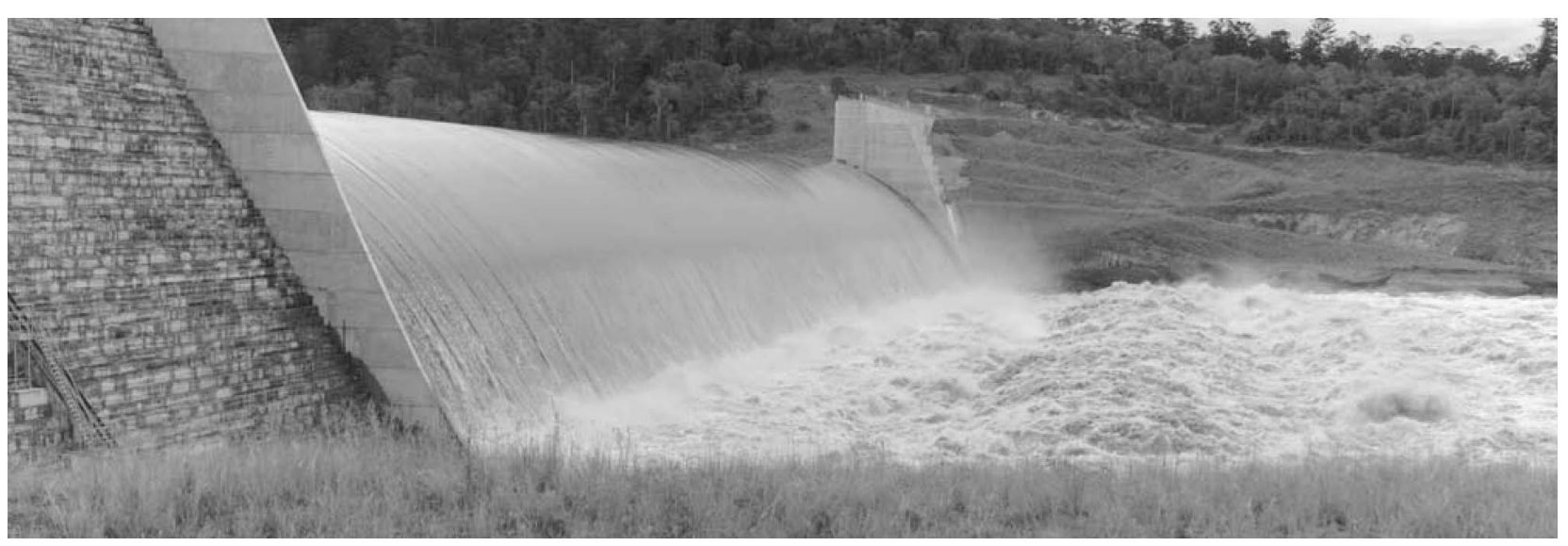

Figure 1: Hydraulic jump stilling basin in operation downstream of Paradise dam spillway (Australia) on 30 Dec. $2010-Q=$ $6,300 \mathrm{~m}^{3} / \mathrm{s}, \operatorname{Re}=1.9 \times 10^{7}$

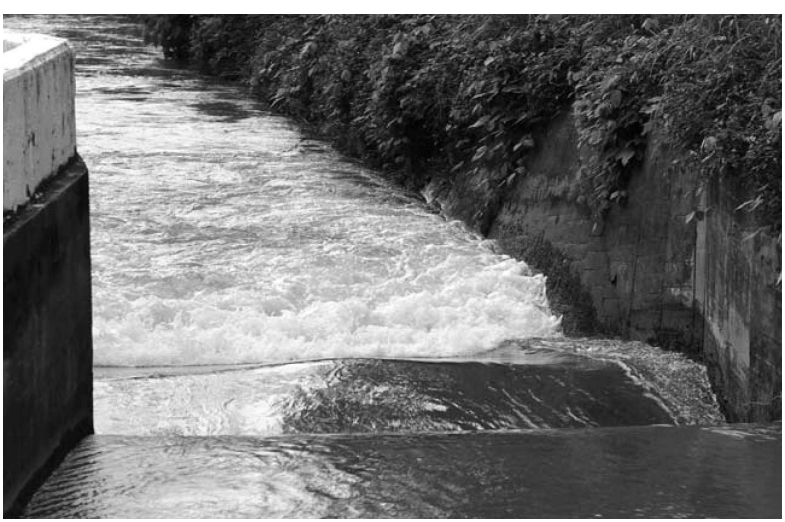

Figure 2 : Hydraulic jump in an irrigation channel at Taroko (Taiwan) on 10 Nov. 2010 - Flow from foreground right to background left

between the flow properties upstream and downstream of the jump [20], [15], [28], [52]:

$$
\begin{gathered}
V_{1} A_{1}=V_{2} A_{2} \\
\rho V_{1} A_{1}\left(\beta_{2} V_{2}-\beta_{1} V_{1}\right)=\iint_{A_{1}} P d A-\iint_{A_{2}} P d A-F_{f r i c}+W \sin \theta
\end{gathered}
$$

where $\mathrm{V}$ is the cross-sectional-averaged flow velocity, A is the cross-section area, $\rho$ is the water density assumed constant, $g$ is the gravity acceleration, $\beta$ is a momentum correction coefficient, $\mathrm{P}$ is the pressure, the subscripts 1 and 2 refer respectively to the upstream and downstream flow conditions, $\mathrm{F}_{\text {fric }}$ is the flow resistance force, $\mathrm{W}$ is the weight force and $\theta$ is the angle between the bed slope and horizontal (Fig. 4). The upstream and downstream flow conditions are referred to as conjugate flow conditions. Equations (1) and (2) are valid for a stationary hydraulic jump in an irregular channel and may be extended to hydraulic jumps in translation (surges, bores).

In Equation (2), the difference in pressure forces may be derived assuming a hydrostatic pressure distribution upstream and downstream of the hydraulic jump. The net pressure force resultant consists of the increase of pressure $\rho g\left(d_{2}-d_{1}\right)$ applied to the upstream flow cross-section $A_{1}$ plus the pressure force on the area $\Delta \mathrm{A}$ defined in Figure 4 , where

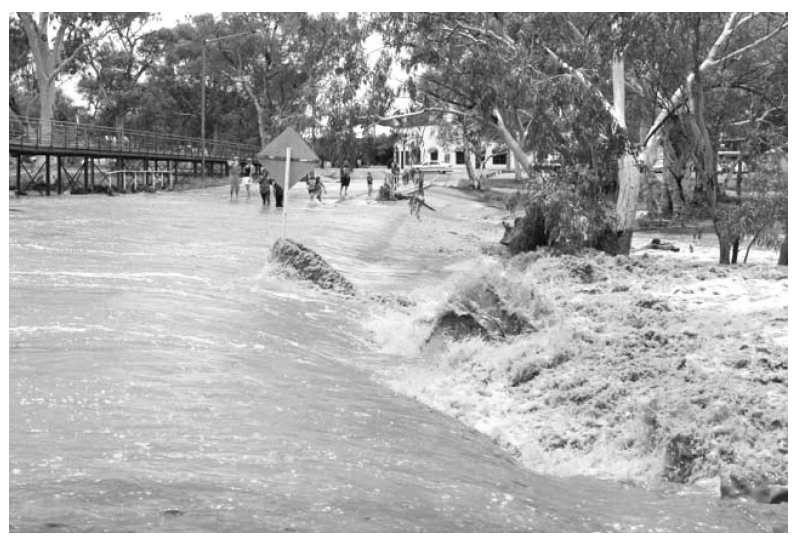

Figure 3 : Hydraulic jump in the Todd River (Alice Springs NT, Australia) in Jan. 2007 (Courtesy of Mrs Sue McMinnBavin) - Flow from left to right, note the dark brown colour of the water that is evidence of heavy sediment load - The Todd River is an ephemeral river that flows only a few times per year

$d_{1}$ and $d_{2}$ are the upstream and downstream flow depths (Fig. 4). Neglecting the flow resistance $\left(\mathrm{F}_{\text {fric }}=0\right)$, the effect of the velocity distribution $\left(\beta_{1}=\beta_{2}=1\right)$ and for a flat horizontal channel $(\theta=0)$, the combination of the continuity and momentum principle gives a series of relationships between the flow properties in front of and behind the jump:

$$
\frac{A_{2}}{A_{1}}=\frac{1}{2} \frac{\sqrt{\left(2-\frac{B^{\prime}}{B}\right)^{2}+8 \frac{B^{\prime}}{B_{1}} F r_{1}^{2}}-\left(2-\frac{B^{\prime}}{B}\right)}{\frac{B^{\prime}}{B}}
$$

where $\mathrm{Fr}_{1}$ is the upstream Froude number: $\mathrm{Fr}_{1}=\mathrm{V}_{1} /$ $\sqrt{g A_{1} / B_{1}}, \mathrm{~B}_{1}$ is the initial free-surface width (Fig. 4), and the characteristic widths $\mathrm{B}$ and $\mathrm{B}$ ' are defined as:

$$
\begin{gathered}
B=\frac{A_{2}-A_{1}}{d_{2}-d_{1}}, \\
B^{\prime}=2 \frac{\iint_{A_{1}}^{A_{2}} \int\left(d_{2}-y\right) d A}{\left(d_{2}-d_{1}\right)^{2}},
\end{gathered}
$$




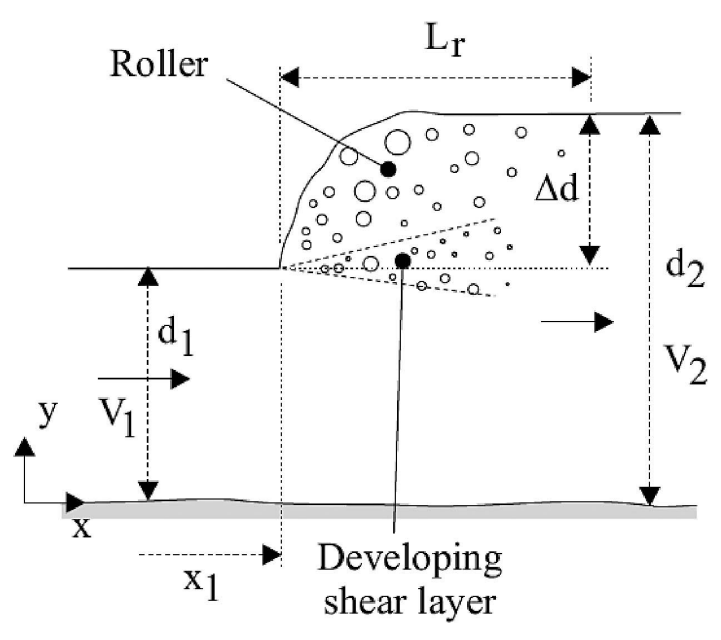

Figure 4 : Sketch of a hydraulic jump in an irregular channel

Equation (3) gives an analytical solution of the cross-sectional ratio $\mathrm{A}_{2} / \mathrm{A}_{1}$ as a function of the upstream Froude number $\mathrm{Fr}_{1}$, the ratio $\mathrm{B}$ '/ $\mathrm{B}$ and the ratio $\mathrm{B}_{1} / \mathrm{B}$. For a rectangular channel $\left(B=B^{\prime}=B_{1}\right)$, the result (Eq. (3)) may be simplified into the Bélanger equation [2], [8]:

$$
\frac{d_{2}}{d_{1}}=\frac{1}{2}\left(\sqrt{1+8 F r_{1}^{2}}-1\right)
$$

In presence of some flow resistance, the combination of the continuity and momentum principles for a hydraulic jump on a horizontal channel $(\theta=0)$ yields:

$$
F r_{1}^{2}=\frac{1}{2} \frac{A_{2}}{A_{1}} \frac{B_{1}}{B}\left(\left(2-\frac{B^{\prime}}{B}\right)+\frac{B^{\prime}}{B} \frac{A_{2}}{A_{1}}\right)+\frac{A_{2}}{A_{2}-A_{1}} \frac{F_{\text {fric }}}{\rho g \frac{A_{1}^{2}}{B}},
$$

For a given Froude number, the solution of Equation (7) implies a smaller ratio of the conjugate cross-sectional areas, hence a smaller ratio of conjugate depths, with increasing flow resistance to satisfy the momentum principle. The finding is consistent with physical data in rectangular channels [43], [27], [40], and it applies to any cross-sectional shape. Note that the effects of flow resistance decrease with increasing Froude number, becoming small for upstream Froude numbers greater than 2 to 4 depending upon the cross-sectional properties and bed roughness. In absence of friction, Equation (7) gives back Equation (3).

\section{II.2. Dynamic similarity}

Detailed analytical, physical and numerical studies of hydraulic jumps require a large number of relevant equations to describe the three-dimensional air-water turbulent flow motion. The relevant parameters needed for the dimensional analysis include the fluid properties and physical constants, the channel geometry and inflow conditions, and the airwater turbulent flow properties characteristics [22]. For a hydraulic jump in a horizontal, rectangular channel, the relevant length scale is the upstream flow depth $d_{1}$ and a simplified dimensional analysis yields:

$$
\begin{aligned}
& \frac{d}{d_{1}}, \frac{d^{\prime}}{d_{1}}, \frac{F_{t o e} d_{1}}{V_{1}}, C, \frac{V}{V_{1}}, \frac{v^{\prime}}{V_{1}}, \frac{D_{a b}}{d_{1}}, \frac{F d_{1}}{V_{1}}, \ldots \\
& =f_{1}\left(\frac{x-x_{1}}{d_{1}}, \frac{y}{d_{1}}, \frac{z}{d_{1}}, \frac{x_{1}}{d_{1}}, \frac{v_{1}{ }^{\prime}}{V_{1}}, \frac{\delta}{d_{1}}, \frac{V_{1}}{\sqrt{g d_{1}}}, \rho \frac{V_{1} d_{1}}{\mu}, \frac{g \mu^{4}}{\rho \sigma^{3}}, \ldots\right),
\end{aligned}
$$

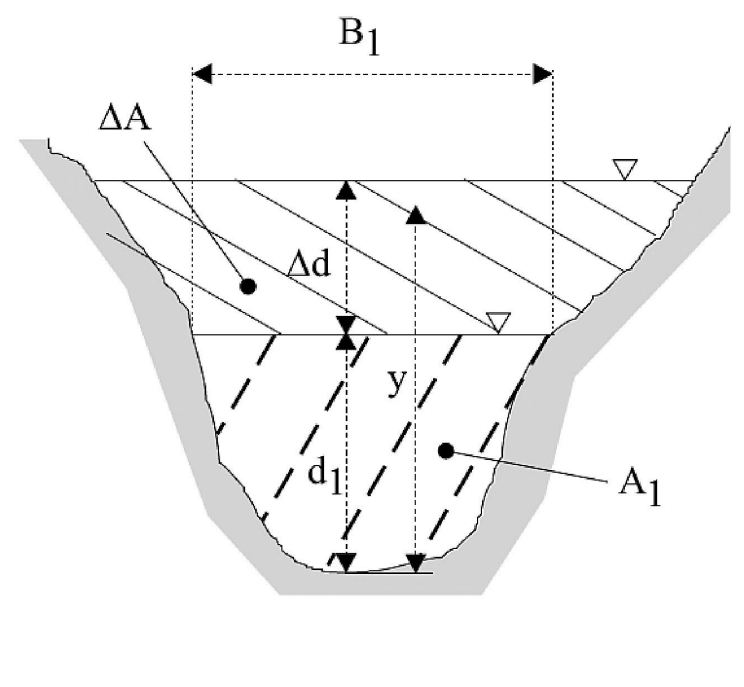

where $d$ is the free-surface elevation, $d$ ' is a characteristic free-surface fluctuation, $F_{\text {toe }}$ is the jump toe fluctuation frequency, $\mathrm{C}$ is the void fraction, $\mathrm{V}$ is the velocity, $\mathrm{v}$ ' is a characteristic turbulent velocity, $\mathrm{D}_{\mathrm{ab}}$ is a characteristic size of entrained bubbles, $\mathrm{F}$ is the bubble count rate, $\mathrm{x}$ is the longitudinal coordinate, $\mathrm{y}$ is the vertical elevation above the invert, $\mathrm{z}$ is the transverse coordinate measured from the channel centreline, $x_{1}$ is the longitudinal coordinate of the jump toe, $v_{1}$ ' is a characteristic turbulent velocity at the inflow, $\delta$ is the boundary layer thickness of the inflow, $\rho$ and $\mu$ are the water density and dynamic viscosity respectively, $\sigma$ is the surface tension between air and water. Equation (8) gives an expression of the air-water turbulent flow properties at a position $(\mathrm{x}, \mathrm{y}, \mathrm{z})$ along the hydraulic jump roller as functions of the inflow properties, channel geometry and fluid properties. In the right handside, the 7th, 8th and 9th terms are respectively the upstream Froude number $\mathrm{Fr}_{1}$, the Reynolds number Re and the Morton number Mo. The above analysis does not take into account the characteristics of any instrumentation nor the mesh size of a numerical model. With a numerical investigation, the quality of the results is closely linked with the type of grid and mesh size selection [17], [31]. In a physical investigation, the size of a probe sensor, the sampling rate and possibly other probe characteristics do affect the minimum size detectable by the measurement system. To date most systematic studies of scale effects affecting air entrainment processes were conducted with the same instrumentation and sensor size [9]: i.e., the probe sensor size was not scaled down in the small size models.

When the study is performed on the centreline of a wide channel, using the same fluids (air and water) in both model and prototype, the flow is basically two-dimensional and the Morton number becomes an invariant. Equation (8) may be simplified into:

$$
\begin{aligned}
\frac{d}{d_{1}}, \frac{d^{\prime}}{d_{1}}, \frac{F_{\text {toe }} d_{1}}{V_{1}}, C, \frac{V}{V_{1}}, \frac{v^{\prime}}{V_{1}}, \frac{D_{a b}}{d_{1}}, \frac{F d_{1}}{V_{1}}, . . \\
=f_{2}\left(\frac{x-x_{1}}{d_{1}}, \frac{y}{d_{1}}, \frac{x_{1}}{d_{1}}, \frac{v_{1}{ }^{\prime}}{V_{1}}, \frac{\delta}{d_{1}}, F r_{1}, \operatorname{Re}\right),
\end{aligned}
$$

In free-surface flows including hydraulic jump studies, the gravity effects are important as shown by Equations (3) and (9). The Froude dynamic similarity is commonly used [39], 
[28] and will be considered herein. It is however impossible to satisfy simultaneously the Froude and Reynolds similarities with a geometrically-similar model. For example, the turbulence properties and air entrainment process are adversely affected by significant scale effects in small size models [44], [53], [5]. Scale effects in turbulent hydraulic jump studies were detailed recently [12], [35].

\section{BASIC FLOW PATTERNS AND FREE- SURFACE PROPERTIES}

The hydraulic jump is classified in terms of its upstream Froude number $\mathrm{Fr}_{1}$. For a Froude number slightly above unity, the jump front is followed by a series of stationary free-surface undulations. This is the undular hydraulic jump [25], [13], [7]. For Froude numbers larger than 2 to 3, the jump has a marked turbulent roller region associated some highly turbulent motion with large-scale vortical structures and an air-water flow region (Fig. 1 to 3) [21], [48]. Some basic features of the turbulent jump include the strong spray and splashing above the jump toe and roller, as well the flow discontinuity at the impingement point that is a source of vorticity and of entrained air bubbles. Figure 5 shows two high-shutter speed photographs of the jump toe, illustrating the variety of short-lived air-water structures projected above the hydraulic jump. Both photographs were taken looking downstream at the jump toe, the impingement perimeter and the associated free-surface discontinuity.

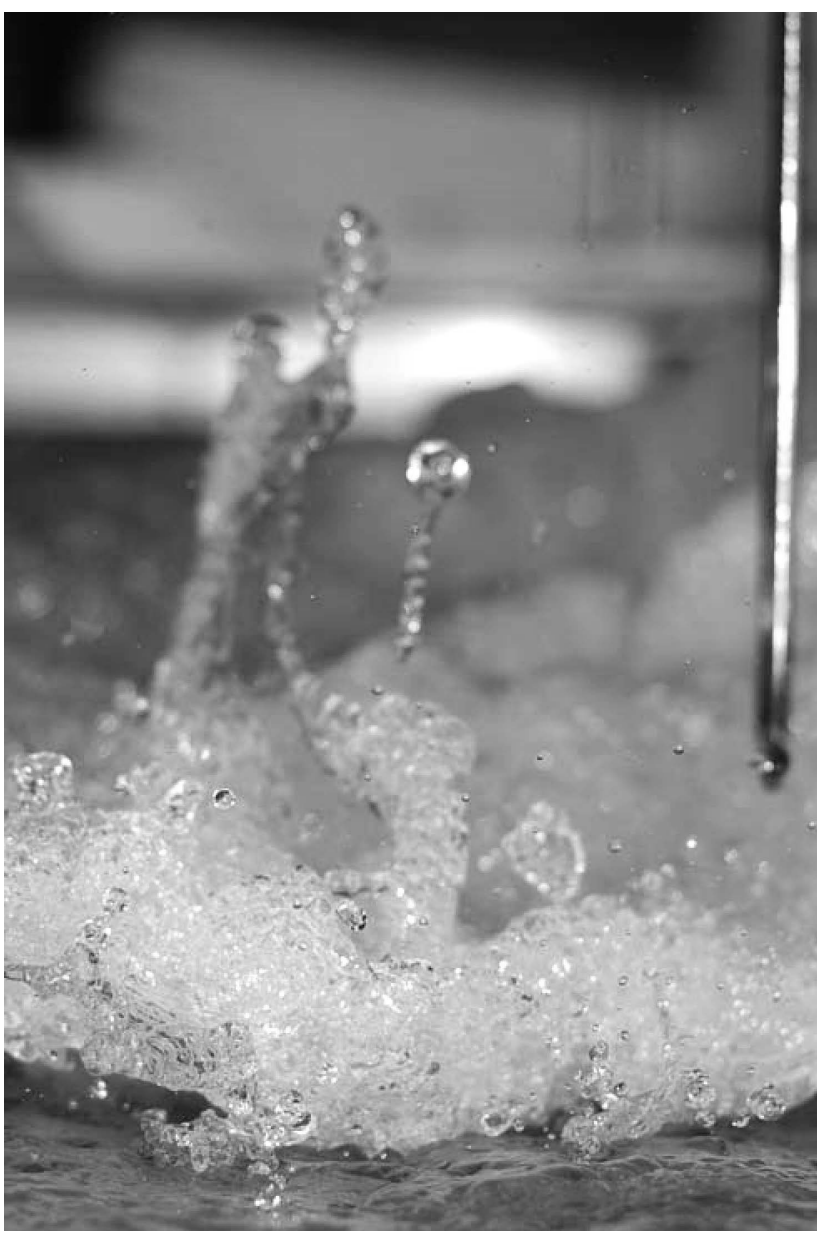

(A) $\mathrm{d}_{1}=0.0405 \mathrm{~m}, \mathrm{x}_{1}=1.5 \mathrm{~m}, \mathrm{Fr}_{1}=4.32, \mathrm{Re}=1.1 \times 10^{5}$
In the remaining paragraphs, the focus is on the turbulent jump with a marked roller.

\section{III.1. Free-surface profiles and turbulent fluctuations}

Some typical free-surface profiles of turbulent hydraulic jumps are presented in Figure 6 for Froude numbers ranging from 2.4 to 8.5 . The data sets were collected using nonintrusive acoustic displacement meters. Figure 6A presents the longitudinal distributions of mean water depth $\mathrm{d}$ and standard deviations d' of the water elevations as functions of the dimensionless distance $\left(\mathrm{x}-\mathrm{x}_{1}\right)$ from the jump toe. The physical data show some longitudinal profiles that are very close to the photographic observations through the glass sidewalls and to classical results [1], [45]. Overall the longitudinal free-surface elevations present a self-similar profile:

$$
\frac{d-d_{1}}{d_{2}-d_{1}}=\left(\frac{x-x_{1}}{L_{r}}\right)^{0.441}, \quad 2.4<\mathrm{Fr}_{1}<8.5
$$

where $L_{r}$ is the roller length. Equation (10) is compared with experimental data in Figure 6B together with the theoretical solution of Valiani [51].

The longitudinal distributions of the water elevation standard deviation d' show a significant increase in free surface fluctuations immediately downstream of the jump toe (Fig. 6A). A peak of turbulent fluctuations (d') ${ }_{\text {max }}$ is observed in the first half of the roller typically as seen in Figure 6A

Figure 5 : High-shutter speed photographs of air-water projections in hydraulic jumps, looking downstream at the impingement point and free-surface discontinuity at the jump toe - Flow from foreground to background 


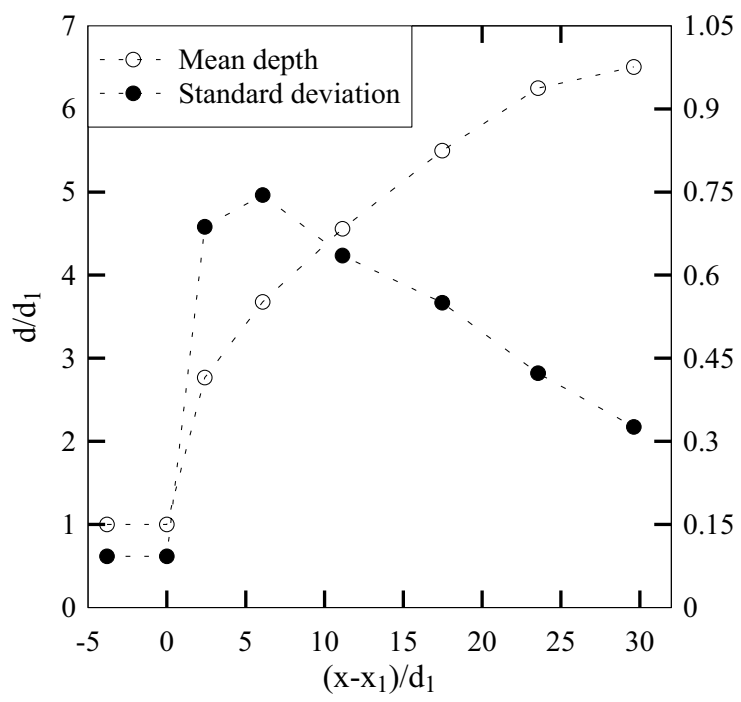

(A) Mean free-surface profile and standard deviation for $\mathrm{Fr}_{1}=5.1$

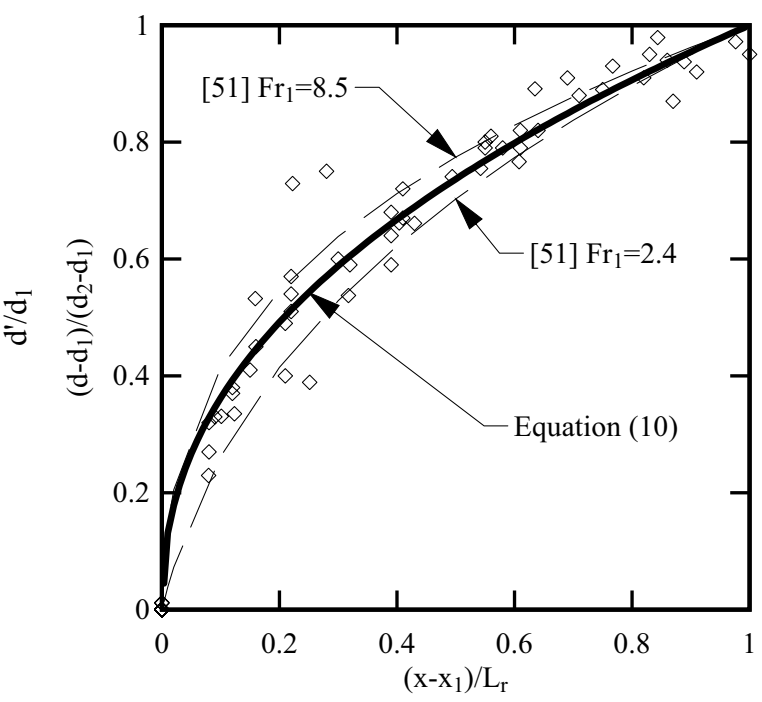

(B) Self-similar free-surface profiles for $2.4<\mathrm{Fr}_{1}<8.5$. Comparison with Equation (10) and Valiani's solution [51]

Figure 6 : Free-surface profiles of turbulent hydraulic jumps (Data: Murzyn and Chanson [36], Chachereau and Chanson [3])

[33], [36], [3]. In Figure 6A, the maximum standard deviation of the free-surface elevation is nearly 0.75 times the inflow depth $\left(\left(\mathrm{d}^{\prime}\right)_{\max } \approx 0.75 \mathrm{~d}_{1}\right)$ for $\mathrm{Fr}_{1}=5.1$. The free surface becomes more turbulent with increasing Froude number, and the physical data demonstrate a monotonic increase in maximum free-surface fluctuations with increasing Froude number at the power 1.235. This is seen in Figure 7 presenting $\left(d^{\prime}\right)_{\max } / d_{1}$ as a function of the upstream Froude number $\mathrm{Fr}_{1}$.

Since the flow properties upstream and downstream of the jump must satisfy the momentum equations, the Bélanger equation (Eq. (6)) may be compared with some physical data in Figure 8. The results show a close agreement between the data and theory neglecting boundary friction and flow resistance.

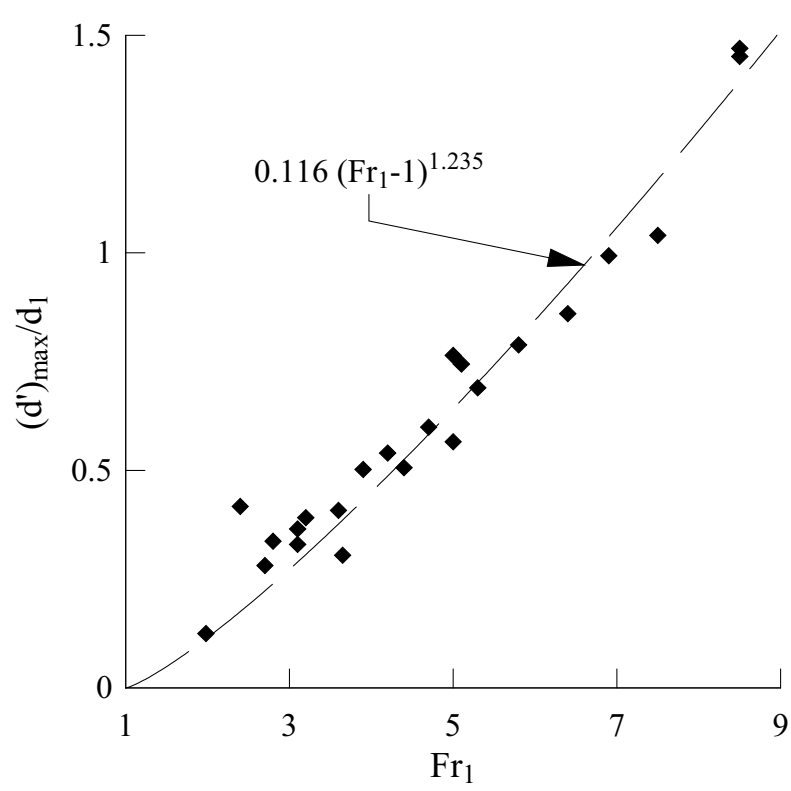

Figure $7:$ Maximum of turbulent fluctuations $\left(d^{\prime}\right)_{\max } / d_{1}$ in turbulent jump rollers as a function of Froude number $\mathrm{Fr}_{1}$ (Data: Mouazé et al. [33], Kucukali and Chanson [23], Murzyn and Chanson [36], Chachereau and Chanson [3])
In a smooth channel, the longitudinal position of the hydraulic jump toe fluctuates with time. The jump toe pulsations are believed to be caused by the growth, advection, and pairing of large-scale vortices in the developing shear layer of the jump [30]. The dimensionless jump toe frequency $\mathrm{F}_{\text {toe }} \mathrm{d}_{1} / \mathrm{V}_{1}$ ranges between 0.003 and 0.006 independently of the upstream Froude number. For comparison, the characteristic frequency $\mathrm{F}_{\mathrm{fs}}$ of the free-surface fluctuations tends to be larger at small Froude numbers. The re-analysis of several data sets yielded [3]:

$$
\frac{F_{f s} d_{1}}{V_{1}}=0.143 \exp \left(-0.27 F r_{1}\right), \quad 2.4<\mathrm{Fr}_{1}<6.5
$$

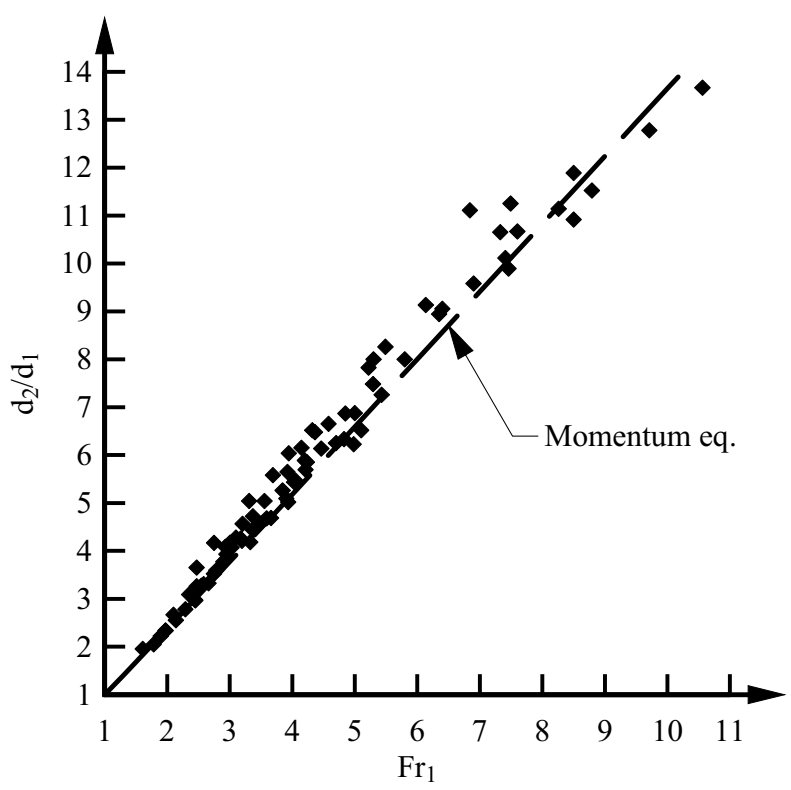

Figure 8 : Ratio of conjugate depths $d_{2} / d_{1}$ for hydraulic jumps in horizontal rectangular channels - Comparison between the Bélanger equation (Eq. (6)) and experimental data (Data: Murzyn et al. [38], Chanson [8,], [10], Murzyn and Chanson [36], Chachereau and Chanson [3]) 


\section{III.2. Free-surface turbulent time and length scales}

In two independent studies [33], [3], the free-surface fluctuations were recorded simultaneously at two locations with known, controlled separations distances. The data analyses yield the integral free-surface time and length scales and some results are presented in Figure 9. The turbulent freesurface scales characterise the coherent structures acting next to the free-surface of the hydraulic jump roller. The integral free-surface length scales $\mathrm{L}_{\mathrm{xx}}$, and $\mathrm{L}_{\mathrm{xz}}$ increase with increasing distance from the jump toe (Fig. 9A). The longitudinal length scale $\mathrm{L}_{\mathrm{x}}$, ranges from $1.2 \mathrm{~d}_{1}$ to $3.5 \mathrm{~d}_{1}$, and the transverse length scale $\mathrm{L}_{\mathrm{xz}}$ from $1.2 \mathrm{~d}_{1}$ to $2.6 \mathrm{~d}_{1}$, for longitudinal positions $\left(x-x_{1}\right) / d_{1}$ between 7 and 23 . The results are linked with the inflow Froude number Fr1 and the data sets are best fitted by:

$$
\begin{aligned}
& \frac{L_{x x^{\prime}}}{d_{1}}=0.112 \frac{x-x_{1}}{d_{1}}+\left(3.02-0.545 F r_{1}\right), 2.4<\mathrm{Fr}_{1}<5.1 \\
& \frac{L_{x z}}{d_{1}}=0.0627 \frac{x-x_{1}}{d_{1}}+\left(2.54-0.371 F r_{1}\right), 2.4<\mathrm{Fr}_{1}<5.1
\end{aligned}
$$

At a given longitudinal location for a given Froude number, the longitudinal integral length scale is slightly larger than the transverse length scale, implying that the turbulence was not homogeneous at the free surface of the hydraulic jump.

The integral turbulent time scale data exhibit a linear increase with increasing distance from the jump toe for a given Froude number (Fig. 9B). The trend is linked with an increase in large coherent structure sizes and slower convection velocities with increasing distance from the jump toe. The data are independent of the Froude number, and the integral turbulent time scales were best correlated by:

$$
T_{X} \sqrt{\frac{g}{d_{1}}}=0.4026+0.0172 \frac{x-x_{1}}{d_{1}}, \quad 2.4<\mathrm{Fr}_{1}<5.1
$$

$$
T_{Z} \sqrt{\frac{g}{d_{1}}}=0.4670+0.0132 \frac{x-x_{1}}{d_{1}} \quad 2.4<\mathrm{Fr}_{1}<5.1
$$

The integral time scales are observed to be very similar in the longitudinal and transverse directions, $\mathrm{T}_{\mathrm{X}}$ and $\mathrm{T}_{\mathrm{Z}}$ respectively, although the integral length scale data show some differences between transverse and longitudinal results (Fig. 9).

\section{AIR-WATER FLOW PROPERTIES}

The analytical and numerical modelling of the air-water mixing zone in turbulent hydraulic jumps is primitive because of the large number of relevant equations to describe the two-phase turbulent flow motion as well as the limited validation data sets [17], [31]. At the same time, the air-water flow measurements have been restricted by the complex nature of the flow, including the high turbulence levels, the strong interactions between entrained air and vortical structures and the recirculation motion in the roller. The traditional monophase flow metrology such as acoustic Doppler velocimetry (ADV), particle image velocimetry (PIV) and laser Doppler anemometry (LDA) is unsuitable. Some specialised multiphase flow techniques include phase detection probes, hot-film probes, fibre phase Doppler anemometry (FPDA) and bubble image velocimetry (BIV), although the latter two techniques are restricted to low void fractions. To date the most successful physical data set were obtained with intrusive phase-detection probes, typically electrical and optical fibre needle probes. A summary of results follows.

\section{IV.1. Basic air-water properties}

The vertical distributions of void fractions $\mathrm{C}$ and bubble count rates $\mathrm{F}$ highlight two main air-water flow regions in the hydraulic jump roller (Fig. 10A). That is, the air-water

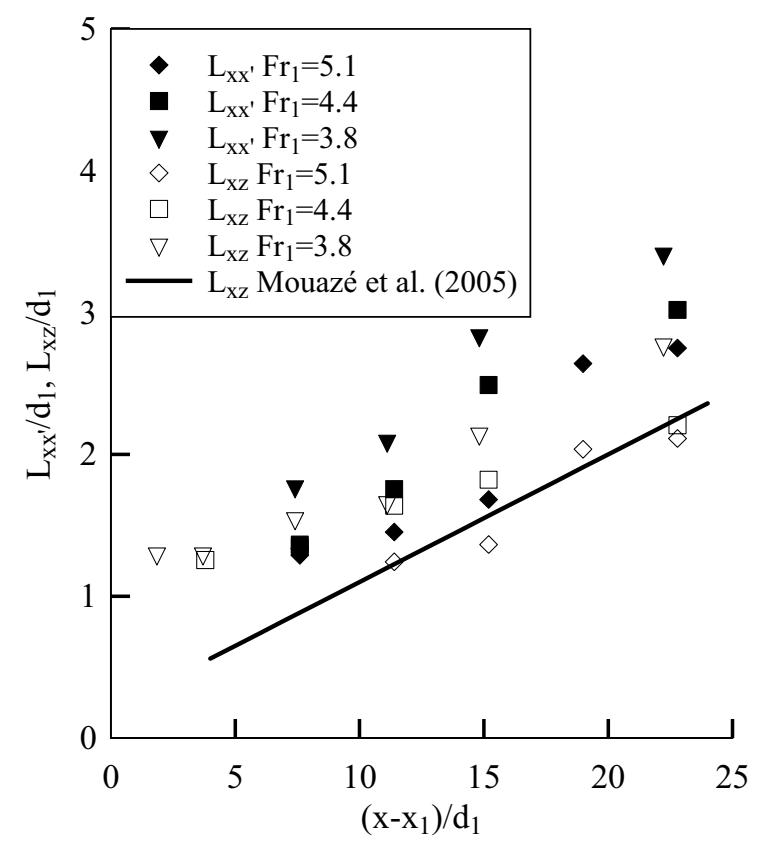

(A) Integral turbulent length scales

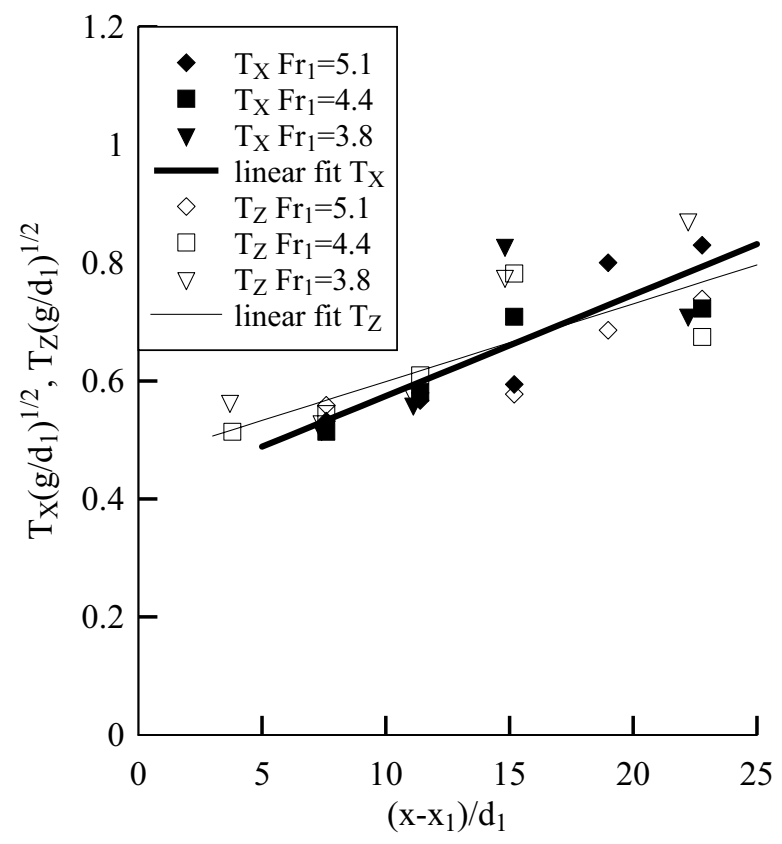

(B) Integral turbulent time scales

Figure 9 : Longitudinal distributions of integral free-surface length and time scales in hydraulic jumps in horizontal rectangular channels - (Data: Mouazé et al. [33], Chachereau and Chanson [3]) 
(A) Definition sketch

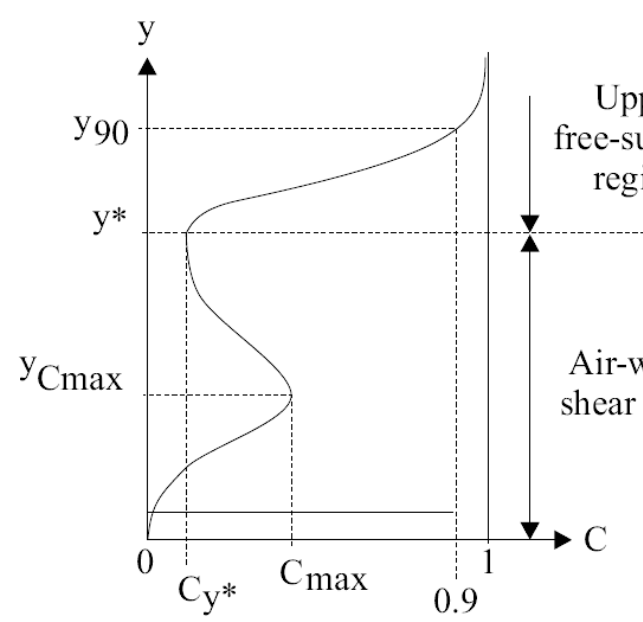

(B) $\mathrm{d}_{1}=0.0395 \mathrm{~m}, \mathrm{Fr}_{1}=5.1, \mathrm{Re}=.1 .3 \times 10^{5}$

(Data: Chachereau and Chanson [3])

Comparison with Equation (14)
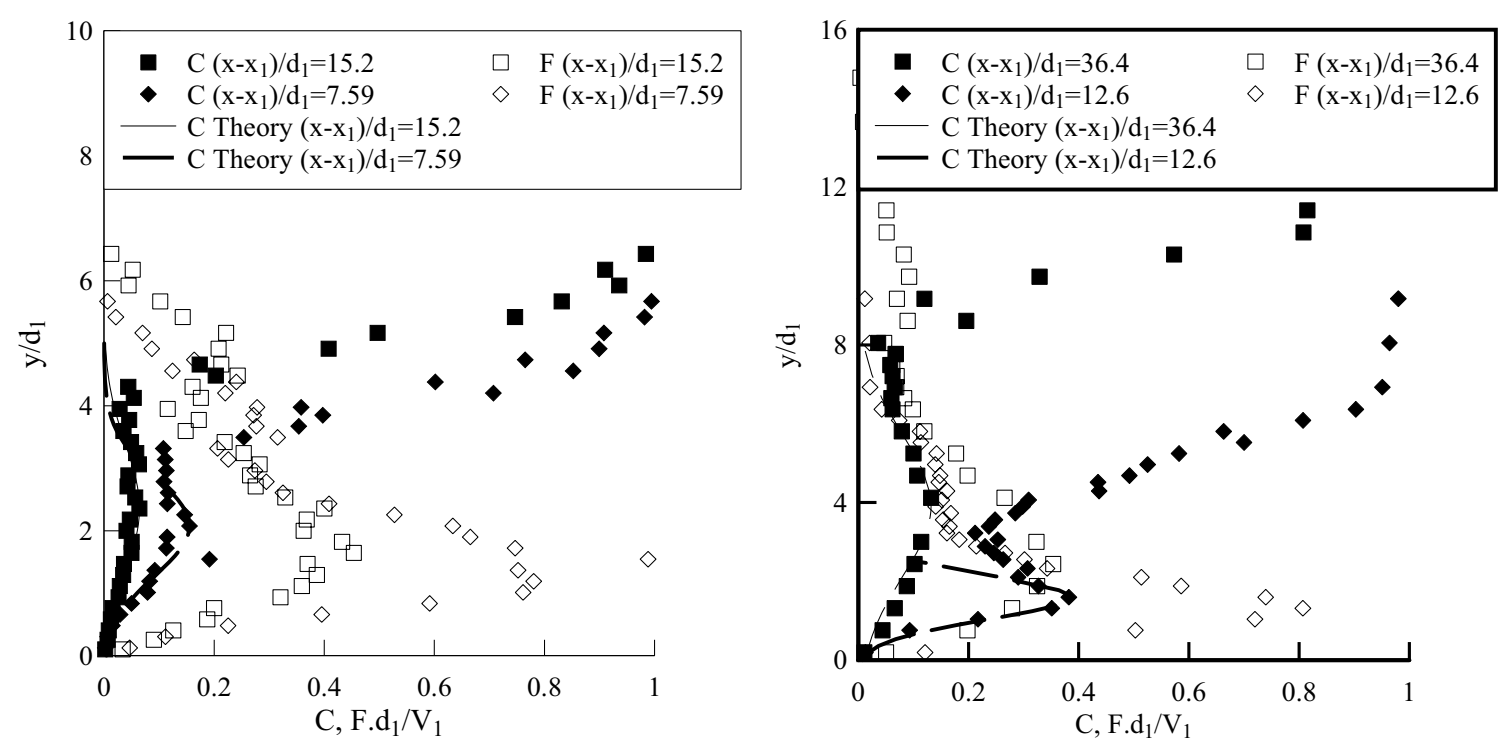

Figure 10 : Vertical distributions of void fraction and bubble count rate in turbulent hydraulic jumps

shear layer and the upper free-surface region. Herein the bubble count rate $\mathrm{f}$ is defined as the number of bubbles detected by the probe sensor per second. The developing shear layer is characterised by some strong interactions between the entrained air bubbles and the vortical structures, associated with a local maximum in void fraction $\mathrm{C}_{\max }$ and a maximum bubble count rate $\mathrm{F}_{\max }$. In the shear layer, the distributions of void fractions follow an analytical solution of the advective diffusion equation for air bubbles:

$$
C=\frac{\frac{Q_{\text {air }}}{Q}}{\sqrt{4 \pi D^{\#} X^{\prime}}}\left(\exp \left(-\frac{\frac{\left(y^{\prime}-1\right)^{2}}{X^{\prime}}}{4 \times D^{\#}}\right)+\exp \left(-\frac{\frac{\left(y^{\prime}+1\right)^{2}}{X^{\prime}}}{4 \times D^{\#}}\right)\right),
$$

where $\mathrm{Q}_{\text {air }}$ is the entrained air volume, $\mathrm{Q}$ is the water discharge, $\mathrm{D}^{\#}$ is a dimensionless air bubble diffusivity typically derived from the best data fit, $\mathrm{X}^{\prime}=\mathrm{X} / \mathrm{d}_{1}, \mathrm{y}^{\prime}=\mathrm{y} / \mathrm{d}_{1}$, $X=x-x_{1}+u_{r} / V_{1} \times y, \mathrm{u}_{\mathrm{r}}$ is the bubble rise velocity [10]. In the upper free-surface region above, the void fraction increases monotically with increasing distance from the bed from a local minimum $\mathrm{C}_{\mathrm{y}^{*}}$ to unity. Figures $10 \mathrm{~B}$ and $10 \mathrm{C}$ present some typical vertical distributions of void fraction and bubble count rate.

The air-water interfacial velocity distributions in the shear zone exhibit a self-similar profile that is close to that of monophase wall jet flows [42], [11]:

$$
\begin{gathered}
\frac{V}{V_{\max }}=\left(\frac{y}{Y_{V \max }}\right)^{\frac{1}{N}}, \quad \text { for } \frac{y}{Y_{V \max }}<1 \\
\frac{V-V_{\text {recirc }}}{V_{\max }-V_{\text {recirc }}}=\exp \left(-\frac{1}{2}\left[1.765\left(\frac{y-Y_{V \max }}{y_{0.5}}\right)\right]^{2}\right), \\
\text { for } 1<\frac{y}{Y_{V \max }}<3 \text { to } 4
\end{gathered}
$$

where $\mathrm{V}_{\max }$ is the maximum velocity in a cross-section measured at $\mathrm{y}=\mathrm{Y}_{\mathrm{V} \max }$. $\mathrm{V}_{\text {recirc }}$ is the recirculation velocity mea- 

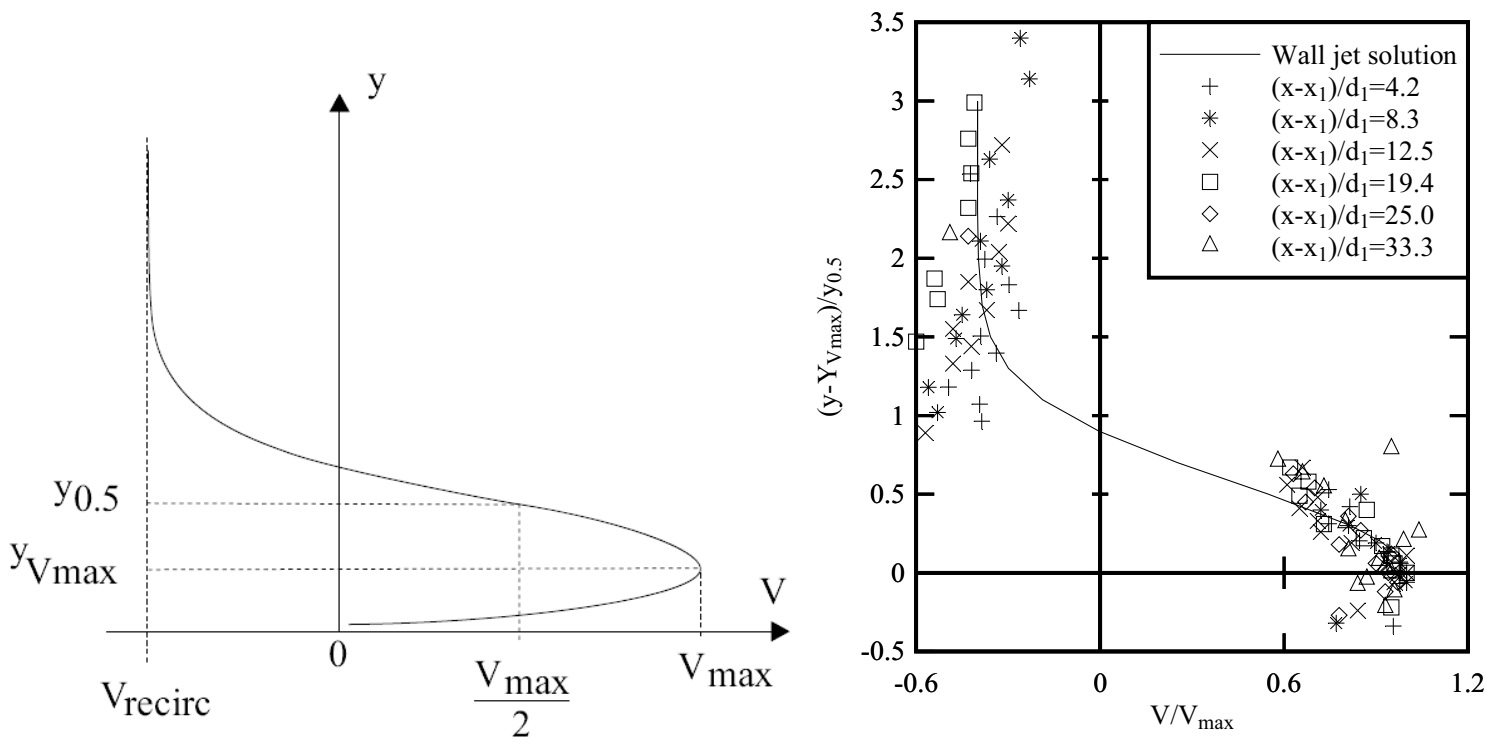

(A) Definition sketch

(B) $\mathrm{d}_{1}=0.018 \mathrm{~m}, \mathrm{Fr}_{1}=10.0, \mathrm{Re}=7.5 \times 10^{4}$

(Data: Chanson [10])

Figure 11 : Vertical distributions of interfacial velocity in hydraulic jumps

sured in the upper free-surface region, $\mathrm{y}_{05}$ is the vertical elevation where $\mathrm{V}=\mathrm{V}_{\max } / 2$ and $\mathrm{N}$ is a constant $(\mathrm{N} \approx 6)$ (Fig. 11A). Equation (15a) expresses the no-slip condition imposed at the bed: $\mathrm{V}(\mathrm{y}=0)=0$. Equation (15b) is compared with physical data in Figure 11B. The maximum velocity $\mathrm{V}_{\max }$ decays exponentially with increasing distance from the jump toe. Experimental data compare favourably with an empirical correlation:

$$
\begin{aligned}
& \frac{V_{\max }}{V_{1}}=\exp \left(-0.028 \frac{x-x_{1}}{d_{1}}\right), \\
& \qquad \text { for } 0<\frac{x-x_{1}}{d_{1}}<80 \& 5.1<\mathrm{Fr}_{1}<11.2
\end{aligned}
$$

with a trend similar to wall jet and monophase hydraulic jump flow data [29]. In the recirculation region above the shear layer, the time-averaged recirculation velocity $\mathrm{V}_{\text {recirc }}$ is negative, and some data sets yield in average: $\mathrm{V}_{\text {recirc }}^{\text {recirc }} / \mathrm{V}_{\max } \sim-0.4[10]$.

The turbulence intensity distributions show some very high levels of turbulence in the shear zone, possibly linked with the bubble-induced turbulence in the jump shear region. Further the turbulence levels increase with increasing distance from the bed $y / d_{1}$ and with increasing Froude number. The former trend would be consistent with Prandtl mixing length theory as well as monophase hydraulic jump flow data [29], [26]. The distributions of air-water integral turbulent length scales show similarly a monotonic increase with increasing distance from the invert (Fig. 12). The air-water integral turbulent length scale $\mathrm{L}_{\mathrm{xz}}$ characterises a characteristic size of large vortical structures advecting the air bubbles in the hydraulic jump roller [6]. Typical results are presented in Figure 12.

\section{IV.2. Air-water flow structures}

The time-averaged air-water properties such as the void fraction, bubble count rate and air-water interfacial velocity are gross, macroscopic parameters that do not give any information on the microscopic structure of the two-phase

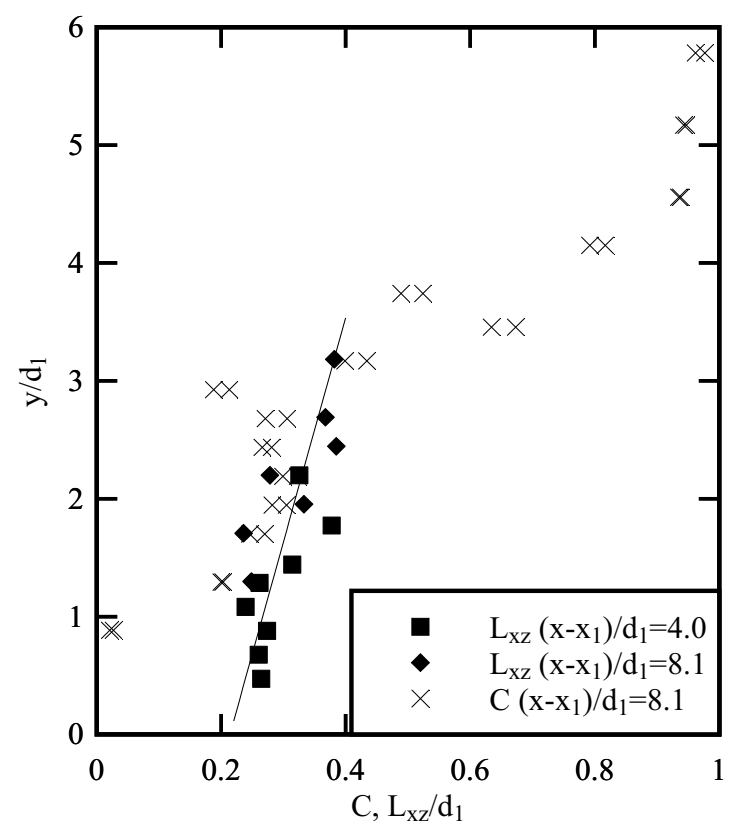

Figure 12 : Vertical distributions of integral air-water turbulent length scales and void fraction in hydraulic jumps Data: Chanson [6], $d_{1}=0.0245 \mathrm{~m}, \mathrm{Fr}_{1}=7.9, \mathrm{Re}=9.4 \times 10^{4}$

flow. Phase detection probes can provide further details on the longitudinal pattern of air and water structures including bubbles, droplets, and air-water packets.

In the hydraulic jump, a phase-detection intrusive probe cannot discriminate accurately the direction of the velocity, and the most reliable information is the air and water chord time data: i.e, the detection times of bubbles/droplets by the probe sensor. Figure 13 shows some typical normalised distributions of bubble chord time in the hydraulic jump shear layer (Fig. 13A) and droplet chord time distributions in the upper spray region (Fig. 13B). For each graph, the histogram columns represent each the probability of particle chord time 


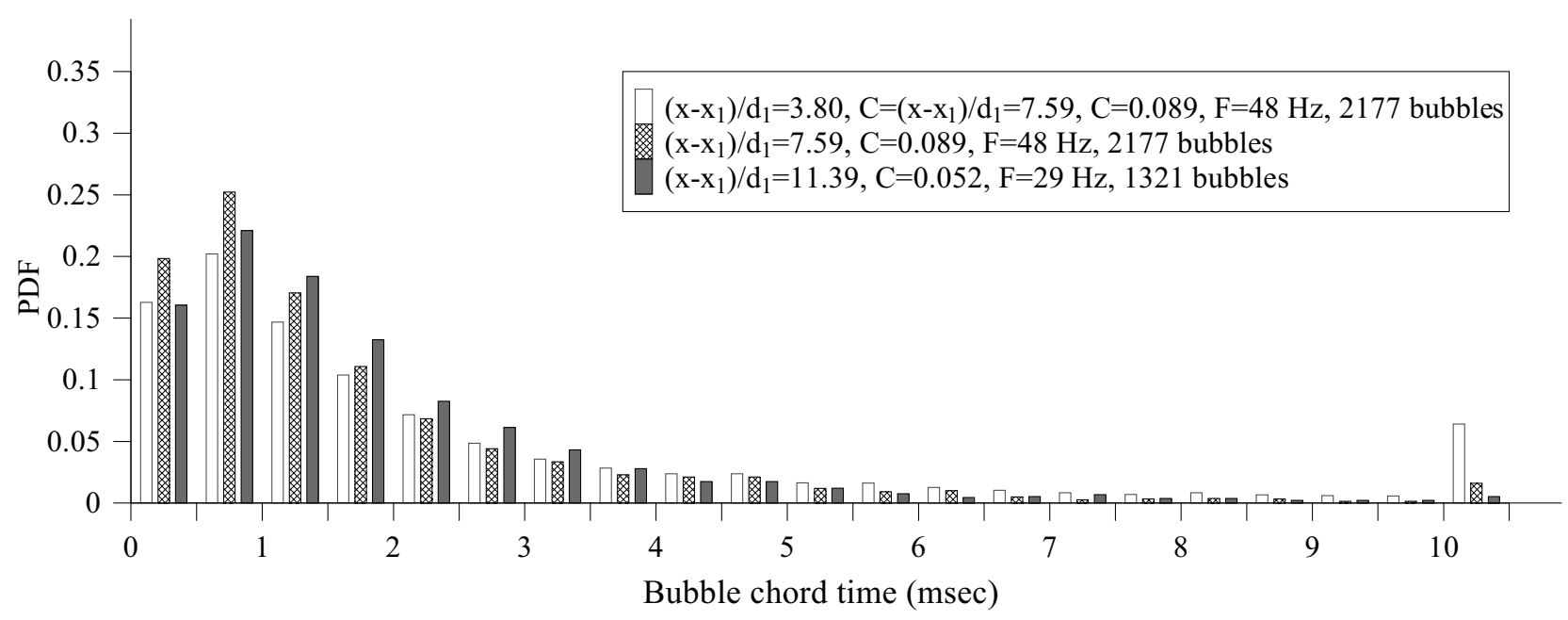

(A) Bubble chord time PDFs in the air-water shear layer $-\mathrm{d}_{1}=0.0405, \mathrm{Fr}_{1}=3.8, \mathrm{Re}=9.8 \times 10^{4}$ (Data: Chachereau and Chanson [3])

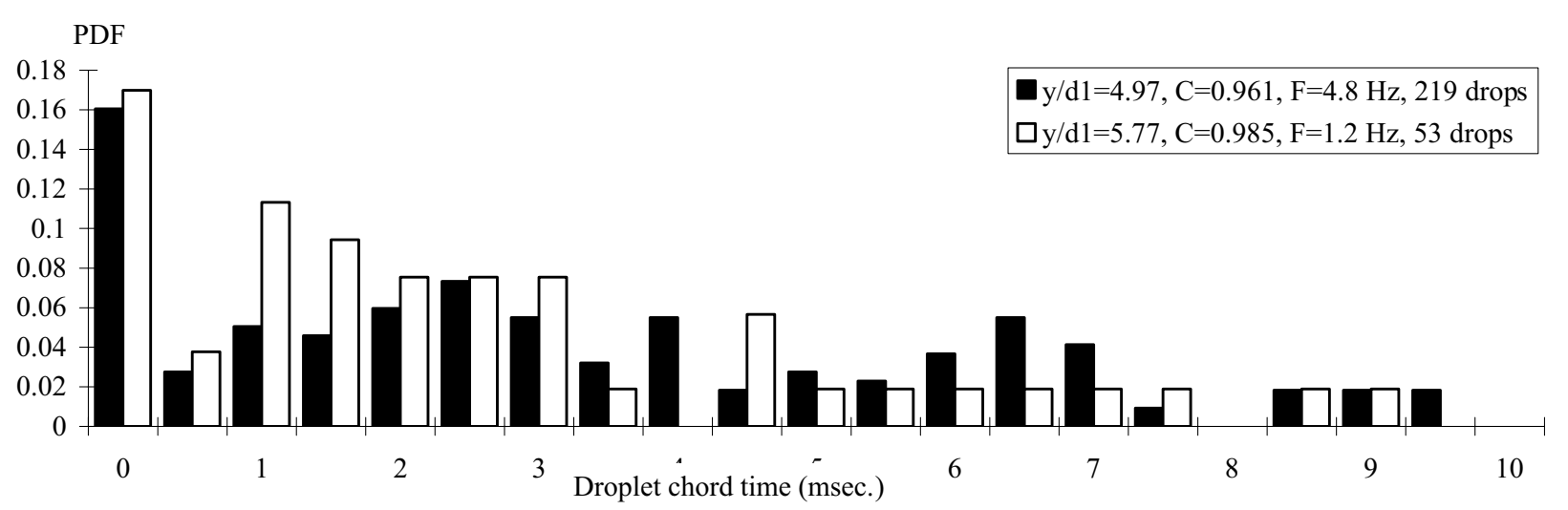

(B) Droplet chord time PDFs in the spray region above the upper free-surface region $-\mathrm{d}_{1}=0.0265, \operatorname{Fr}_{1}=5.1, \operatorname{Re}=6.8 \times 10^{4}$, $\mathrm{x}-\mathrm{x}_{1}=0.2 \mathrm{~m}$ (Data: Chanson [6])

Figure 13 : Normalised probability distribution functions (PDF) of air/water chord time in hydraulic jumps

in a $0.5 \mathrm{~ms}$ chord time interval. For example, the probability of air chord time from 1 to $1.5 \mathrm{~ms}$ is represented by the column labelled $1 \mathrm{~ms}$. Air-water chord times larger than $10 \mathrm{~ms}$ are not shown for better readability. Overall the physical data sets show a broad spectrum of bubble and droplet chord times in the hydraulic jumps. The range of chord times extends over several orders of magnitude, including at low void fractions, from less than $0.1 \mathrm{~ms}$ to more than $10 \mathrm{~ms}$. More the distributions are skewed with a preponderance of small air/water chord times relative to the mean. In the shear zone, the probability distribution functions of bubble chord time tend to follow in average a log-normal distribution, and a similar finding was observed in plunging jet flows [16], [14].

In addition the probe signal outputs provide some details on the longitudinal pattern of air-water structures including bubble clustering. The study of clustering events may be useful to infer if the formation frequency responds to some particular frequencies of the flow. A concentration of particles within some relatively short time intervals may indicate some clustering, or it may be the consequence of a random occurrence. Figure 14 shows the occurrence of pairing in time in the developing shear layer of a hydraulic jump. The binary pairing indicator is unity if the water chord time between adjacent bubbles is smaller than the lead particle chord time and zero otherwise. The grouping of vertical lines in Figure 14 is an indication of patterns in which bubbles tend to form bubble clusters. A clustering analysis method may be based upon the study of water chord between two adjacent bubbles/droplets. If two particles are closer than a particular length scale, they can be considered a group/cluster of bubbles/droplets. The characteristic water length scale may be related to the water/air chord statistics: e.g., a bubble/droplet cluster may be defined when the water chord was less than a given percentage of the median water/ air chord. Another criterion may be linked with the nearwake of the lead particle, since the trailing particle may be influenced by the leading particle wake. A complementary method may be based upon an inter-particle arrival time analysis. The inter-particle arrival time is defined as the time between the arrivals of two consecutive particles. The distribution of inter-particle arrival times may provide some information on the randomness of the structure within some basic assumptions. A randomly dispersed flow is one whose inter-particle arrival time distributions follow inhomogeneous Poisson statistics assuming non-interacting point particles. An ideally dispersed flow is driven by a superposition of Poisson processes of particle sizes. Hence any deviation from a Poisson process would infer particle clustering. Both critera were applied to hydraulic jump flows [6], [18]. 


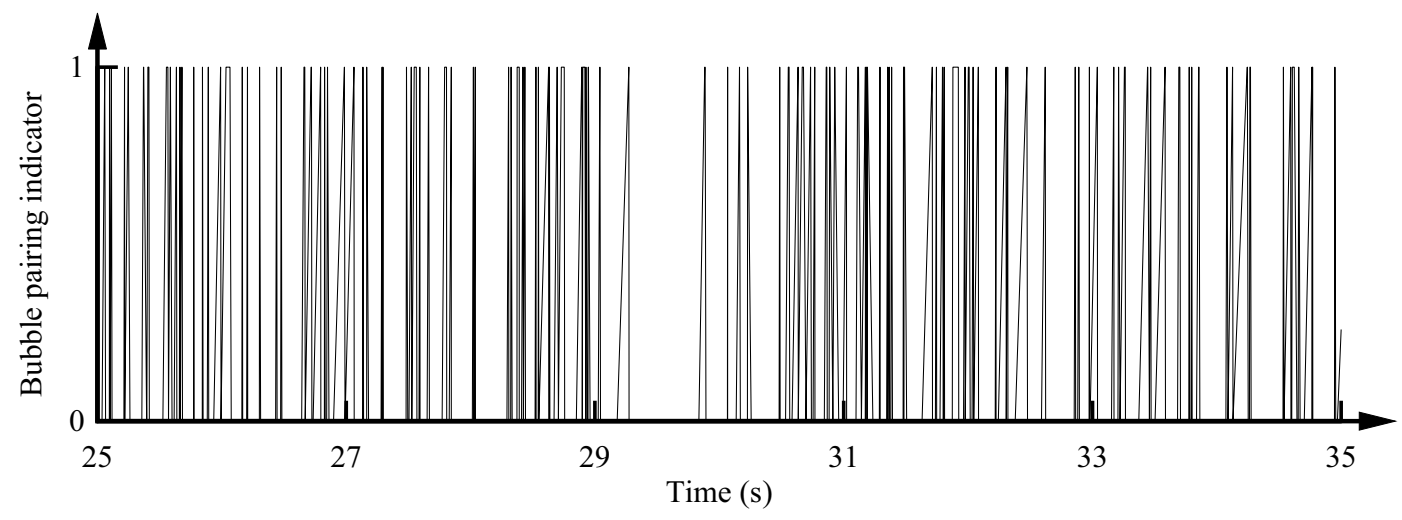

Figure 14: Binary pairing indicator of closely spaced bubble pairs in the developing shear layer of a hydraulic jump $(1=$ water chord time smaller than once the lead bubble chord time (i.e. near wake); $0=$ otherwise $)-d_{1}=0.0405 \mathrm{~m}, F r_{1}=$ 3.8, $R e=9.7 \times 10^{4},\left(x-x_{1}\right) / d_{1}=3.7, y / d_{1}=1.19, C=0.11, F=53.8 \mathrm{~Hz}$ (Data: Chachereau and Chanson [3])

Figure 15 presents some typical results of bubble clustering analyses in the developing shear layer of turbulent hydraulic jumps. It shows the longitudinal distributions of the percentage of bubbles in clusters for several upstream Froude numbers. For these data sets, two bubbles are considered parts of a cluster when the water chord time between two consecutive bubbles is less than the bubble chord time of the lead particle. That is, when a bubble trails the previous bubble by a short time/length, it is in the near-wake of and could be influenced by the leading particle. Note that the cluster criterion is based upon a comparison between the local, instantaneous characteristic time scales of the airwater flow, and it is independent of the local air-water flow properties. The results highlight that a large proportion of bubbles are parts of a cluster structure in the air-water shear zone (Fig. 15), while the percentage of bubbles in clusters decreases with increasing longitudinal distance.

Interestingly all the cluster analysis methods tend to yield relatively close results independently of the cluster definition criterion. They show a large proportion of cluster bubbles close to the impingement point, implying some very strong interactions between entrained air bubbles and vortical structures in the developing shear layer. The decay in number of cluster bubbles with longitudinal distance implies some lesser bubble-turbulence interactions further downstream. It must be stressed however that the approach only applies to the longitudinal air-water structures, and it does not consider particles travelling side by side.

\section{CONCLUSION}

This article reviews the progress and development in the understanding of hydraulic jumps. The focus is on the turbulent hydraulic jump with a marked roller operating with high-Reynolds numbers that is commonly encountered in natural rivers and man-made structures (Fig. 1 to 3 ). These hydraulic jumps are characterised by the highly turbulent

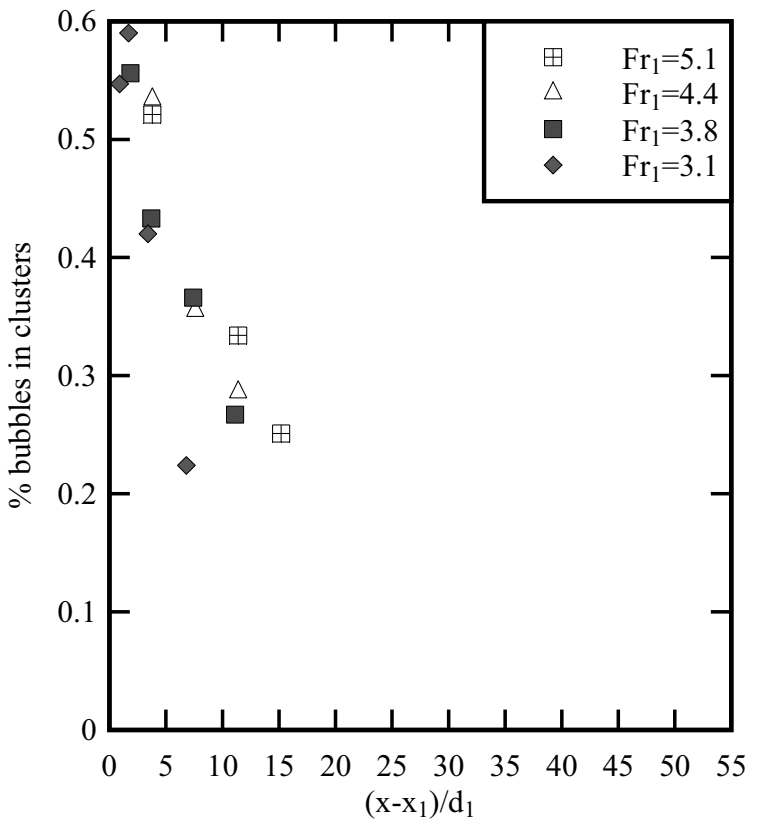

(A) Hydraulic jumps with relatively small inflow Froude numbers (Data: Chachereau and Chanson [3])

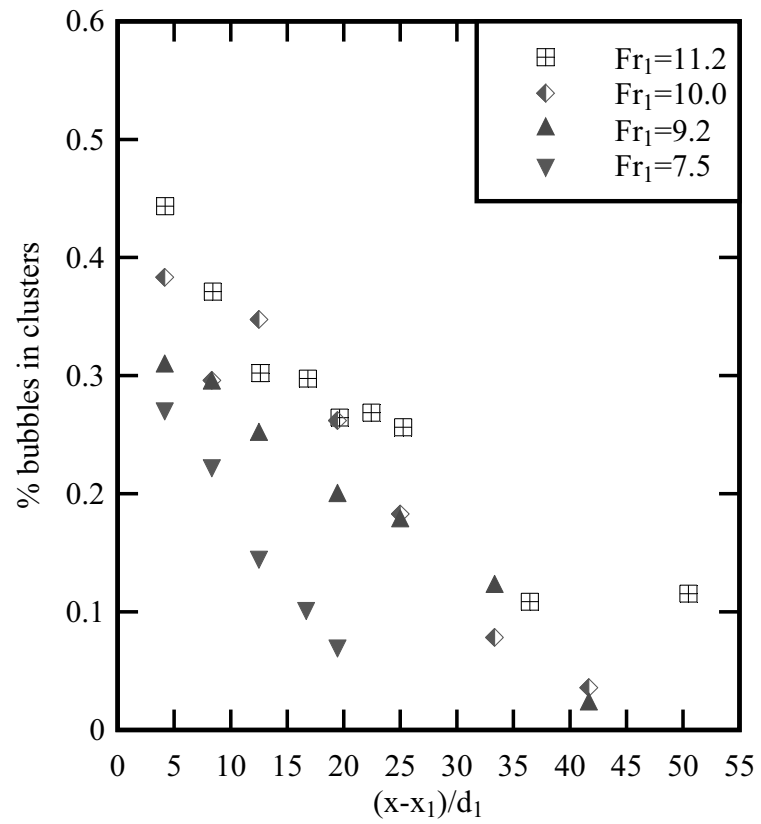

(B) Hydraulic jumps with relatively large inflow Froude numbers (Data: Chanson [10])

Figure 15 : Percentage of bubbles in clusters in the air-water shear layer of hydraulic jumps at locations where $F=F_{\text {max }}-$ Cluster criterion: water chord time smaller than once the lead bubble chord time (i.e. near wake) 
nature of the flow and intense air bubble entrainment at the jump toe.

Some theoretical considerations show that the basic dimensionless parameter is the upstream Froude number $\mathrm{Fr}_{1}=\mathrm{V}_{1} / \sqrt{g A_{1} / B_{1}}$. A dimensional analysis suggests that some viscous scale effects may take place in small geometrically-similar models. Some detailed free-surface measurements highlight the fluctuating nature of the free-surface. The maximum free-surface fluctuations are proportional to the upstream Froude number at the power 1.2. The free-surface integral length and time scales increase with increasing distance from the jump toe, and the differences between longitudinal and transverse integral scales imply that the turbulence is not homogeneous at the free surface of the hydraulic jump.

The air-water flow measurements in turbulent hydraulic jumps highlight two flow regions: a developing shear layer and an upper free-surface region. The air-water shear layer is characterised by a local maximum in void fraction, a maximum bubble count rate and an interfacial velocity distribution that follows a shape close to a wall jet profile. The air/ water chords in the developing shear layer present a broad spectrum of bubble/droplet chord times in the hydraulic jumps. The range of chord time extends over several orders of magnitude, including at low void fractions, and the distributions are skewed with a preponderance of small air/water chord times relative to the mean. Some clustering analyses show a large percentage of cluster bubbles particularly close to the entrapment point, implying some very strong interactions between the entrained air and the vortical structures.

In a natural stream, however, the hydraulic jump flow is a three-phase flow motion characterised by intense sediment motion as illustrated in Figure 3. Such a flow motion is challenging as shown by Macdonald et al. [24].

\section{ACKNOWLEDGMENTS}

The author thanks his former students and co-workers, including Dr Peter Cummings, Ms Qiao Gaolin, Tim Brattberg, Dr Sergio Montes, Dr Carlo Gualtieri, Dr Serhat Kucukali, Dr Frédéric Murzyn, Ben Hopkins, Hugh Cassidy, and Yann Chachereau. He thanks further Graham Illidge, Ahmed Ibrahim, and Clive Booth (The University of Queensland) for their technical assistance. He acknowledges the helpful comments of the reviewers. The financial support of the Australian Research Council (Grant DP0878922) is acknowledged.

\section{REFERENCES AND CITATIONS}

[1] Bakhmeteff B.A., and Matzke A.E. (1936) - The Hydraulic Jump in Terms of Dynamic Similarity Transactions. ASCE. 101 $630-647$ et $648-680$

[2] Belanger J.B. (1841) — Notes sur l'Hydraulique ('Notes on Hydraulic Engineering.') Ecole Royale des Ponts et Chaussées, Paris, France, session 1841-1842 (in French). 223 pages

[3] Chachereau Y., and Chanson H. (2010) - Free-surface fluctuations and turbulence in hydraulic jumps. (DOI 10.1016/j. expthermflusci.2011.01.009). Experimental Thermal and Fluid Science. 35 896-909

[4] Chanson H. (1995) - Air Entrainment in Two-Dimensional Turbulent Shear Flows with Partially Developed Inflow Conditions. International Journal of Multiphase Flow. 21(6) 1107-1121
[5] Chanson H. (1997) - Air Bubble Entrainment in FreeSurface Turbulent Shear Flows. Academic Press, London, UK 401 pages

[6] Chanson H. (2007) - Bubbly Flow Structure in Hydraulic Jump (DOI: 10.1016/j.euromechflu.2006.08.001). European Journal of Mechanics B/Fluids. 26(3) 367-384

[7] Chanson H. (2009) - Current Knowledge In Hydraulic Jumps And Related Phenomena. A Survey of Experimental Results (DOI: 10.1016/j.euromechflu.2008.06.004). European Journal of Mechanics B/Fluids. 28(2) 191-210

[8] Chanson H. (2009) - Un Hydraulicien d'Exception bien en avance sur son Époque: Jean-Baptiste Charles Joseph Bélanger (1790-1874) ('An Exceptional Hydraulic Engineer ahead of his Time: Jean-Baptiste Charles Joseph Bélanger (1790-1874).') (DOI 10.1051/lhb/2009072) (in French). La Houille Blanche. 5 183-188

[9] Chanson H. (2009) - Turbulent Air-water Flows in Hydraulic Structures: Dynamic Similarity and Scale Effects (DOI: 10.1007/s10652-008-9078-3). Environmental Fluid Mechanics. 9(2) $125-142$

[10] Chanson H. (2010) - Convective Transport of Air Bubbles in Strong Hydraulic Jumps (DOI: 10.1016/j.ijmultiphaseflow.2010.05.006). International Journal of Multiphase Flow. 36(10) $798-814$

[11] Chanson H., and Brattberg T. (2000) — Experimental Study of the Air-Water Shear Flow in a Hydraulic Jump. International Journal of Multiphase Flow. 26(4) 583-607

[12] Chanson H., and Gualtieri C. (2008) - Similitude and Scale Effects of Air Entrainment in Hydraulic Jumps. Journal of Hydraulic Research, IAHR. 46(1) 35-44

[13] Chanson H., and Montes J.S. (1995) - Characteristics of Undular Hydraulic Jumps. Experimental Apparatus and Flow Patterns. Journal of Hydraulic Engineering, ASCE. 121(2) et 123(2) 129-144. et 161-164

[14] Chanson H., Aoki S., and Hoque A. (2006) - Bubble Entrainment and Dispersion in Plunging Jet Flows: Freshwater versus Seawater (DOI:10.2112/03-0112.1). Journal of Coastal Research. 22(3), May 664-677

[15] Chоw V.T. (1973) — Open Channel Hydraulics. McGraw-Hill International, New York, USA

[16] Cummings P.D., and Chanson H. (1997) - Air Entrainment in the Developing Flow Region of Plunging Jets. Part 2: Experimental. Journal of Fluids Engineering, Trans. ASME. 119(3) 603-608

[17] Gonzalez A.E., and Bombardelli F.A. (2005) - Two-Phase Flow Theoretical and Numerical Models for Hydraulic Jumps, including Air Entrainment. Proc. 31st Biennial IAHR Congress, Seoul, Korea, B.H. Jun, S.I. Lee, I.W. Seo and G.W. Choi Editors (CD-ROM)

[18] Gualtieri C., and Chanson H. (2010) - Effect of Froude Number on Bubble Clustering in a Hydraulic Jump (DOI: 10.1080/00221686.2010.491688). Journal of Hydraulic Research, IAHR. 48(4) 504-508

[19] Hager W.H. (1992) — Energy Dissipators and Hydraulic Jump. Kluwer Academic Publ., Water Science and Technology Library. 8288 p

[20] Henderson F.M. (1966) — Open Channel Flow. MacMillan Company, New York, USA

[21] Hoyt J.W., and Sellin R.H.J. (1989) - Hydraulic Jump as 'Mixing Layer. Journal of Hydraulic Engineering, ASCE. 115(12) $1607-1614$

[22] Kobus H. (1984) - Local Air Entrainment and Detrainment. Proc. Int. Symp. on Scale Effects in Modelling Hydraulic Structures, IAHR, Esslingen, Germany

[23] Kucukali S., and Chanson H. (2008) - Turbulence Measurements in Hydraulic Jumps with Partially- 
Developed Inflow Conditions (DOI: 10.1016/j.expthermflusci.2008.06.012). Experimental Thermal and Fluid Science. 33(1) $41-53$

[24] Macdonald R.G., Alexander J., Bacon J.C., and Cooker M.J. (2009) - Flow Patterns, Sedimentation and Deposit Architecture under a Hydraulic Jump on a Non-Eroding Bed: Defining Hydraulic Jump Unit Bars (DOI: 10.1111/j.13653091.2008.01037.x). Sedimentology. 56 1346-1367

[25] Lemoine R. (1948) — Sur les Ondes Positives de Translation dans les Canaux et sur le Ressaut Ondulé de Faible Amplitude ('On the Positive Surges in Channels and on the Undular Jumps of Low Wave Height.') (in French). La Houille Blanche. 2 183-185

[26] Lennon J.M., and Hill D.F. (2006) - Particle Image Velocimetry Measurements of Undular and Hydraulic Jumps. Journal of Hydraulic Engineering. 132(12) 1283-1294

[27] Leutheusser H.J., and Schiller E.J. (1975) - Hydraulic Jump in a Rough Channel. Water Power \& Dam Construction. 27(5) 186-191

[28] Liggett J.A. (1994) — Fluid Mechanics. McGraw-Hill, New York, USA

[29] LiU M., Rajaratnam N., and Zhu D.Z. (2004) — Turbulent Structure of Hydraulic Jumps of Low Froude Numbers. Journal of Hydraulic Engineering, ASCE. 130(6) 511-520

[30] Long D., Rajaratnam N., Steffler P.M., and Smy P.R. (1991) - Structure of Flow in Hydraulic Jumps. Journal of Hydraulic Research, IAHR. 29(2) 207-218

[31] Lubin P. Glockner S., and Chanson H. (2009) - Numerical Simulation of Air Entrainment and Turbulence in a Hydraulic Jump. Proc. Colloque SHF Modèles Physiques Hydrauliques: Outils Indispensables du XXI Siècle?, Société Hydrotechnique de France, Lyon, France, 24-25 Nov. 109-114

[32] Mossa M., and Tolve U. (1998) - Flow Visualization in Bubbly Two-Phase Hydraulic Jump. Journal Fluids Engineering, ASME. 120 160-165

[33] Mouazé D., Murzyn F., and Chaplin J.R. (2005) - Free Surface Length Scale Estimation in Hydraulic Jumps. Journal of Fluids Engineering, Trans. ASME. 127 1191-1193

[34] Murzyn F. (2010) - Assessment of Different Experimental Techniques to Investigate the Hydraulic Jump: Do They Lead to the Same Results? Hydraulic Structures: Useful Water Harvesting Systems or Relics?, Proc. 3rd International Junior Researcher and Engineer Workshop on Hydraulic Structures (IJREWHS'10), 2-3 May 2010, Edinburgh, Scotland, $R$. Janssen and H. Chanson (Eds), Hydraulic Model Report CH80/10, School of Civil Engineering, The University of Queensland, Brisbane, Australia. 3-36

[35] Murzyn F., and Chanson H. (2008) - Experimental Assessment of Scale Effects Affecting Two-Phase Flow Properties in Hydraulic Jumps (DOI: 10.1007/s00348-0080494-4). Experiments in Fluids. 45(3) 513-521

[36] Murzyn F., and Chanson H. (2009) - Free-Surface Fluctuations in Hydraulic Jumps: Experimental Observations (DOI: 10.1016/j.expthermflusci.2009.06.003). Experimental Thermal and Fluid Science. 33(7) 1055-1064

[37] Murzyn F., Mouazé D., and Chaplin J.R. (2005) - Optical Fibre Probe Measurements of Bubbly Flow in Hydraulic Jumps. International Journal of Multiphase Flow. 31(1) 141154
[38] Murzyn F., Mouazé D., and Chaplin J.R. (2007) - Air-Water Interface Dynamic and Free Surface Features in Hydraulic Jumps. Journal of Hydraulic Research, IAHR. 45(5) 679-685

[39] NovaK P., and CabelKa J. (1981) - Models in Hydraulic Engineering. Physical Principles and Design Applications. Pitman Publ., London, UK.

[40] Pagliara S., Lotti I., and Palermo M. (2008) - Hydraulic Jump on Rough Bed of Stream Rehabilitation Structures. Journal of Hydro-Environment Research. 2(1) 29-38

[41] Rajaratnam N. (1962) - An Experimental Study of Air Entrainment Characteristics of the Hydraulic Jump. Jl of Instn. Eng. India. 42(7) 247-273

[42] Rajaratnam N. (1965) - The Hydraulic Jump as a Wall Jet. Journal of Hydraulic Division, ASCE, Vol. 91, No. HY5, pp. 107-132. Discussion. 91(HY5), 92( HY3), 93(HY1) 107$132,110-123,74-76$

[43] Rajaratnam N. (1968) - Hydraulic Jumps on Rough Beds. Trans. Engrg. Institute of Canada. 11(A-2) I-VIII

[44] Rao N.S.L., and Kobus H.E. (1971) - Characteristics of SelfAerated Free-Surface Flows. Water and Waste Water/Current Research and Practice, Eric Schmidt Verlag, Berlin, Germany. 10

[45] ReHBock T. (1929) - The River Hydraulic Laboratory of the Technical University of Karlsruhe. Hydraulic Laboratory Practice, ASME, New York, USA. 111-242

[46] Resch F.J., and Leutheusser H.J. (1972) - Reynolds Stress Measurements in Hydraulic Jumps. Journal of Hydraulic Research, IAHR. 10(4) 409-430

[47] Resch F.J., and Leutheusser H.J. (1972) - Le Ressaut Hydraulique: mesure de Turbulence dans la Région Diphasique ('The Hydraulic Jump: Turbulence Measurements in the TwoPhase Flow Region.') (in French). La Houille Blanche. 4 279293

[48] Rodríguez-Rodríguez J., Marugán-Cruz C., Aliseda A., and LAsheras J.C. (2011) - Dynamics of Large Turbulent Structures in a Steady Breaker. (DOI 10.1016/j.expthermflusci.2010.09.012). Experimental Thermal and Fluid Science. 35 301-310

[49] Rouse H., Siao T.T., and Nagaratnam S. (1959) — Turbulence Characteristics of the Hydraulic Jump. Transactions, ASCE. 124 926-950

[50] Thandaveswara B.S. (1974) - Self Aerated Flow Characteristics in Developing Zones and in Hydraulic Jump s. Ph.D. thesis, Dept. of Civil Engrg., Indian Institute of Science, Bangalore, India. 399 pages

[51] Valiani A. (1997) — Linear and Angular Momentum Conservation in Hydraulic Jump. Journal of Hydraulic Research, IAHR. 35(3) 323-354

[52] Viollet P.L., Chabard J.P., Esposito P., et Laurence D. (2002) - Mécanique des Fluides Appliquée. Ecoulements Incompressibles dans les Circuits, Canaux et Rivières, autour des Structures et dans l'Environnement. (Applied Fluid Mechanics. Incompressible Flows in Pipes, Channels and Rivers, around Structures and in the Environment.') Presses des Ponts et Chaussées, Paris, France, $2^{\mathrm{e}}$ édition (in French). 367 pages

[53] Wood I.R. (1991) - Air Entrainment in Free-Surface Flows. IAHR Hydraulic Structures Design Manual, Hydraulic Design Considerations, Balkema Publ., Rotterdam, The Netherlands. 4 149 pages 